\title{
Same-sex sexual behavior and evolution
}

\author{
Nathan W. Bailey and Marlene Zuk
}

Department of Biology, University of California, Riverside, CA 92521, USA

\begin{abstract}
Same-sex sexual behavior has been extensively documented in non-human animals. Here we review the contexts in which it has been studied, focusing on case studies that have tested both adaptive and non-adaptive explanations for the persistence of same-sex sexual behavior. Researchers have begun to make headway unraveling possible evolutionary origins of these behaviors and reasons for their maintenance in populations, and we advocate expanding these approaches to examine their role as agents of evolutionary change. Future research employing theoretical, comparative and experimental approaches could provide a greater understanding not only of how selection might have driven the evolution of same-sex sexual behaviors but also ways in which such behaviors act as selective forces that shape social, morphological and behavioral evolution.
\end{abstract}

\section{Why does same-sex sexual behavior matter?}

Same-sex sexual behavior in animals has long fascinated scientists as well as non-scientists. Previous work has emphasized the apparent paradox of selection acting on non-reproductive individuals [1,2], but little is known about the evolutionary consequences of such behavior, whether it occurs as exclusive life-long pairing or as a part of other sexual interactions. The variety and ubiquity of same-sex sexual behavior in animals is impressive; many thousands of instances of same-sex courtship, pair bonding and copulation have been observed in a wide range of species, including mammals, birds, reptiles, amphibians, insects, mollusks and nematodes (Table 1). These observations are likely to be underestimates of the frequency of such interactions, partly because researchers assume that pairs in sexually monomorphic species that are engaging in sexual behavior must be opposite sexes.

From an evolutionary perspective, same-sex behavior has been viewed as a puzzle requiring a special explanation, rather like suicide or adoption of unrelated infants [3]. Why would animals engage in sexual behaviors that do not directly result in reproduction? It is clear that lifelong same-sex orientation is unlikely to evolve and, indeed, few examples of life-long pairings in wild animals exist, but the persistent and well-documented occurrence of same-sex sexual behaviors across nearly all taxonomic groups of animals is worth exploring.

The purpose of this review is to expand our thinking about the evolutionary implications of same-sex behavior in animals. We suggest that the phenomenon needs to be

Corresponding author: Bailey, N.W. (nathanb@ucr.edu).

\section{Glossary}

Alternative reproductive behavior: different methods, mechanisms or strategies for attaining matings found within a single sex. Most often studied in males, alternative mating tactics might be purely behavioral, or might be associated with different morphologies.

Cooperative breeding: social structure in which individuals forgo reproduction and provide care for others' offspring, such as feeding, grooming and protection from predation.

Gay/lesbian: terms describing homosexual orientation in humans. In typical usage, implies a stereotyped set of lifestyle characteristics that might not accurately reflect the daily lives and activities of homosexual people. Often misapplied in the popular media to animals that have been observed to engage in same-sex mating behavior.

Gender: socially constructed characteristics by which humans identify themselves as male or female, for example, 'masculine' versus 'feminine' traits. Biologically male people might self-identify as female gendered, and vice versa. Gender in animals can be difficult, if not impossible, to ascertain, whereas the biological sex of an animal can often be easily observed. Given the lack of evidence that non-human animals form self-identities, and the limitations of studying such internal processes, application of this term to non-human animals should be discouraged.

Homosexual: in animals, this has been used to refer to same-sex behavior that is not sexual in character (e.g. 'homosexual tandem running' in termites), same-sex courtship or copulatory behavior occurring over a short period of time (e.g. 'homosexual mounting' in cockroaches and rams) or long-term pair bonds between same-sex partners that might involve any combination of courting, copulating, parenting and affectional behaviors (e.g. 'homosexual pair bonds' in gulls). In humans, the term is used to describe individual sexual behaviors as well as long-term relationships, but in some usages connotes a gay or lesbian social identity. Scientific writing would benefit from reserving this anthropomorphic term for humans and not using it to describe behavior in other animals, because of its deeply rooted context in human society.

Indirect genetic effect: when genes in one individual alter the phenotype of another, either through a social interaction or by modifying the environment that the second individual experiences. Genetic effects in one individual can thus be considered part of the environment influencing trait expression in other individuals, meaning that environments are dynamic and can evolve, and that traits expressed during interactions are shaped by the evolving social environment.

Pair bond: an enduring, mutually beneficial relationship between a breeding pair of animals that is often characterized by cooperative interactions, shared parenting tasks and grooming behaviors.

Same-sex sexual behavior: actions between members of the same sex that are also attributed to opposite-sex courtship or mating interactions.

Sexual orientation: the stable and enduring internal preference for sameversus opposite-sex sexual interactions and partnering in humans. Might differ from outward identification: one might outwardly identify as heterosexual, yet maintain private homosexual preferences. Sexual orientation is also independent of sexual behavior; one might identify as homosexually oriented, for example, but never engage in any sexual behaviors associated with homosexual orientation. The term is rarely applied to non-human animals in the scientific literature, with the possible exception of domestic rams, a small proportion of which are described as being male oriented [20].

Sexual preference: the sex with which an individual is more likely to engage in sexual behavior, when given a choice. Same-sex preferences arise when an individual forgoes opportunities to engage in sexual activity with members of the opposite sex and engages in sexual activity with members of the same sex, and vice versa. Sexual preference is distinct from sexual orientation. An individual's preference can change rapidly, and represents the manifestation of behavioral choices rather than a stable internal predisposition toward one sex or the other.

Sexual selection: the differential representation of genotypes in the next generation as a result of variation in reproductive success driven by competition for limited mates or fertilization opportunities. 
Table 1. Representative sampling of same-sex sexual behavior across non-human taxa, ranging from observations in a wild setting to genetic manipulations in the laboratory

\begin{tabular}{|c|c|c|c|c|}
\hline Species $^{a}$ & Setting & $\begin{array}{l}\text { Sex of } \\
\text { participants }\end{array}$ & Description & Refs \\
\hline $\begin{array}{l}\text { African bat bugs } \\
\text { (Afrocimex } \\
\text { constrictus) }\end{array}$ & Wild & Males & $\begin{array}{l}\text { Males traumatically inseminate other males in addition } \\
\text { to females, and they possess genital structures which } \\
\text { reduce the negative effects associated with traumatic } \\
\text { insemination. }\end{array}$ & [30] \\
\hline $\begin{array}{l}\text { Bonobos } \\
\text { (Pan paniscus) }\end{array}$ & Wild & $\begin{array}{l}\text { Females } \\
\text { and males }\end{array}$ & $\begin{array}{l}\text { Females spend a considerable amount of time engaged } \\
\text { in same-sex sexual behavior, including genito-genital } \\
\text { rubbing that can culminate in orgasm. To a much } \\
\text { lesser extent, males engage in kissing, fellatio and genital } \\
\text { massage. Same-sex sexual behavior might ease social } \\
\text { tension and facilitate reconciliation among group members. }\end{array}$ & {$[66]$} \\
\hline $\begin{array}{l}\text { Bottlenose dolphins } \\
\text { (Thursiops sp.) }\end{array}$ & Wild & $\begin{array}{l}\text { Females } \\
\text { and males }\end{array}$ & $\begin{array}{l}\text { Bottlenose dolphins show one of the highest rates of same-sex } \\
\text { sexual behavior documented in any animal. Male-male } \\
\text { mounting, genital contact and 'goosing' appear to } \\
\text { strengthen alliances between small groups of males and } \\
\text { provide practice for later opposite-sex encounters. Female- } \\
\text { female sexual behavior also occurs, but to a much lesser extent. }\end{array}$ & [23] \\
\hline $\begin{array}{l}\text { Chinstrap penguins } \\
\text { (Pygoscelis } \\
\text { antarcticus) }\end{array}$ & Captivity & Males & $\begin{array}{l}\text { Penguins in captivity can form long-lasting same-sex } \\
\text { pair bonds and engage in same-sex sexual behaviors, } \\
\text { including copulation. }\end{array}$ & [15] \\
\hline $\begin{array}{l}\text { Common toad } \\
\text { (Bufo bufo) }\end{array}$ & Wild & Males & $\begin{array}{l}\text { Male toads do not discriminate between the sexes and will } \\
\text { amplect males as well as females. Amplected males, } \\
\text { however, produce a stereotyped call that quickly induces } \\
\text { the other male to release. Sex discrimination might not be } \\
\text { favored in this species because male-male amplexus is } \\
\text { not very costly. }\end{array}$ & [67] \\
\hline $\begin{array}{l}\text { Flour beetles } \\
\text { (Tribolium } \\
\text { castaneum) }\end{array}$ & Laboratory & Males & $\begin{array}{l}\text { Forced male-male mounting and copulation occur frequently, } \\
\text { and there is limited evidence that sperm deposited during } \\
\text { homosexual mounting can be indirectly transferred to } \\
\text { a female during subsequent heterosexual copulation. }\end{array}$ & [1] \\
\hline $\begin{array}{l}\text { Fruit flies } \\
\text { (Drosophila } \\
\text { melanogaster) }\end{array}$ & Laboratory & Males & $\begin{array}{l}\text { Males with mutations in the gene genderblind court other } \\
\text { males, as a result of reduced glutamate transmission. } \\
\text { Social experience and mutations in other genes such as } \\
\text { fruitless, satori and white also cause varying degrees of } \\
\text { same-sex courtship and mounting behavior. }\end{array}$ & [4-13] \\
\hline $\begin{array}{l}\text { Garter snakes } \\
\text { (Thamnophis } \\
\text { sirtalis parietalis) }\end{array}$ & Wild & Males & $\begin{array}{l}\text { Some males mimic females in size or pheromone attributes, } \\
\text { and are courted by other males when females are absent. } \\
\text { However, male-male courtship is not likely a result of } \\
\text { mistaken sex recognition; attracting male courtship } \\
\text { might allow solitary males to thermoregulate and } \\
\text { protect themselves. }\end{array}$ & [34] \\
\hline $\begin{array}{l}\text { Guppies } \\
\text { (Poecillia } \\
\text { reticulata) }\end{array}$ & Laboratory & Males & $\begin{array}{l}\text { Males maintained in all-male social environments directed } \\
\text { more courtship displays toward other males than those } \\
\text { kept in mixed-sex environments. This tendency persisted } \\
\text { even after females were introduced into the previously } \\
\text { all-male tanks. }\end{array}$ & [68] \\
\hline $\begin{array}{l}\text { Laysan albatross } \\
\text { (Phoebastria } \\
\text { immutabilis) }\end{array}$ & Wild & Females & $\begin{array}{l}\text { Birds in Hawaiian populations form long-term female- } \\
\text { female pair bonds, which include courtship displays, } \\
\text { copulation, mutual grooming behavior and egg incubation. }\end{array}$ & [35] \\
\hline $\begin{array}{l}\text { Marine snails } \\
\text { (Crepidula } \\
\text { fornicata) }\end{array}$ & $\begin{array}{l}\text { Wild and } \\
\text { laboratory }\end{array}$ & Males & $\begin{array}{l}\text { All snails of this species start out male, and have weak sex } \\
\text { discrimination. If they pair with another male, then one } \\
\text { simply changes sex. Flexibility in sex changing allows for a } \\
\text { weak sex-discrimination system; in a sister species that } \\
\text { is less flexible, male-male pairings are far more rare. }\end{array}$ & [31] \\
\hline $\begin{array}{l}\text { Nematodes } \\
\text { (Caenorhabditis } \\
\text { elegans) }\end{array}$ & Laboratory & $\begin{array}{l}\text { Females } \\
\text { (hermaphrodites) }\end{array}$ & $\begin{array}{l}\text { To study sex differences in mate-finding behavior, the } \\
\text { nervous systems of hermaphrodites, which are essentially } \\
\text { female, were masculinized by overexpressing the gene } \\
\text { fem-3. This caused their attraction to other hermaphrodites, } \\
\text { a typically male behavior. }\end{array}$ & [21] \\
\hline $\begin{array}{l}\text { Rams } \\
\text { (Ovis aries) }\end{array}$ & Captivity & Males & $\begin{array}{l}\text { A small proportion, around } 6 \% \text {, of domesticated rams } \\
\text { displays typical male courtship and copulatory behaviors } \\
\text { toward other males and can be exclusively male oriented } \\
\text { even when estrous females are available. }\end{array}$ & {$[20,69]$} \\
\hline $\begin{array}{l}\text { Zebra finch } \\
\text { (Taeniopygia } \\
\text { guttata) }\end{array}$ & Laboratory & $\begin{array}{l}\text { Females } \\
\text { and males }\end{array}$ & $\begin{array}{l}\text { Females administered estrogen synthesis inhibitors pair } \\
\text { bond with other females, and male deprivation during } \\
\text { juvenile development can cause opposite-sex partner } \\
\text { preferences in both females and males. }\end{array}$ & [17] \\
\hline
\end{tabular}

${ }^{a}$ The 14 species listed here are by no means an exhaustive list of animals exhibiting same-sex behavior, but provide a starting point for readers interested in obtaining further information and examples. 


\section{Box 1. Drosophila: the workhorse of same-sex behavior research}

Over the past two decades, Drosophila researchers have examined a multitude of candidate genes implicated in the genetic and neurological control of sexual behavior. These studies have provided insights into sexual behavior in general, and as a byproduct have illustrated different mechanisms that can independently produce same-sex sexual behavior. What are these mechanisms, and what can we learn from them?

Mutations in a Drosophila gene called fruitless have been known for nearly half a century to cause males to court other males [4] Fruitless codes for transcription factors that yield male-specific courtship behavior, and mutations affecting the functioning of these factors induce varying types and degrees of male-male courtship [5]. However, mutations with similar effects have since been discovered in many other genes, including dissatisfaction, prospero, quick-to-court, transformer, raised, genderblind and white [6-9]. The ways these genes exert their effects differ, sometimes subtly. For example, a receptor gene for volatile pheromones, OR67d, and one for non-volatile pheromones, GR32a, were both found to inhibit male-male courtship. Males that lack functional copies of either gene cannot accurately distinguish the sexes using sex-specific pheromones, and therefore court males as well as females. However, the neural pathways and brain centers that are affected differ markedly between the two types of mutants $[10,11]$.

Neurochemical and social factors can also interact with the underlying genetic blueprint of the Drosophila brain to induce same-sex behavior [12]. For example, a gene named genderblind controls levels of the extracellular chemical glutamate, which regulates pheromone information processing in nerve cells in male fly brains [8]. Mutations in genderblind disrupt males' chemosensory abilities, so that they misinterpret and overreact to chemical signals that distinguish the sexes [8]. As a result, they court both males and females [8]. Exogenous substances can also induce same-sex behavior, for example, ethanol [13]. The presence of the neurotransmitter dopamine is critical for the ethanol effect, however, and dopamine in and of itself can elevate levels of male-male courtship [9].

Male-male courtship in Drosophila is unambiguously influenced by genetic factors. However, what we can truly learn about samesex sexual behavior from Drosophila studies might be limited. The majority of studies focus on genetic mutations that affect the ability of male flies to distinguish sexes through olfactory recognition; as a result, they court males as well as females. This does not imply that they prefer males over females, or that they are same-sex orientated. Olfactory sensing plays an important role in human homosexual orientations (see Box 2), but it would be equally untenable to suggest that if researchers eliminated humans' abilities to detect sex differences, then their subsequent indiscriminate mating behavior represented bisexual or homosexual orientations. The intensely studied Drosophila system presents unrivalled opportunities for examining the genetic bases of same-sex behavior, preferences and orientation. Admirable strides have been made with the first, and we anticipate that future research will begin to disentangle the remaining related, but distinct, concepts.

viewed in a broader framework, and whereas many have speculated on adaptive explanations for same-sex sexual behavior, it can have evolutionary consequences that biologists might not have fully considered. Studying these consequences can lead to a richer understanding of both same-sex behavior and the processes through which selection shapes social interactions, reproductive behavior and even morphology, and we identify several research strategies that can be employed to achieve this.

\section{Categories of same-sex interactions in animals}

We mainly focus on same-sex behavior per se, without inferring anything about the sexual preference or orien- tation of individuals engaging in the behavior. Sexual behavior, sexual preference and sexual orientation are distinct but often conflated concepts (see Glossary). Confusion among them can undermine the clarity and accurate interpretation of scientific research, so here we emphasize that same-sex sexual behaviors are interactions between same-sex individuals that also occur between opposite-sex individuals in the context of reproduction. For example, many Drosophila studies examine genetic mutations that affect pheromone receptors (Box 1). Sex-specific pheromones and their accurate detection are crucial for sex recognition in fruit flies, and alterations in sex-recognition pathways can produce males that court other males, females that court females, or males that switch from same-sex to opposite-sex courtship within minutes [413]. In other words, the mutations cause same-sex sexual behavior. However, this behavior often occurs alongside opposite-sex courtship as well, with males mating indiscriminately $[8,10,11]$. So although they show same-sex sexual behavior, males might not actually be exhibiting a preference for one sex over the other (see Box 1).

Individuals exhibiting a same-sex preference choose to engage in sexual behavior with a member of the same sex, when given the option of engaging in sexual behavior with an opposite-sex individual. Preference implies that the animal has made a choice. Examples of same-sex preferences in non-human animals are far more rare than examples of same-sex behavior. Nevertheless, in the damselfly Ischnura elegans, researchers demonstrated that males exposed to all-male groups preferentially courted other males when they were given a choice between a male and a female [14]. Their preference for one sex over the other was flexible, and could be switched by manipulating the social context they experienced previously [14].

Same-sex orientation implies a more permanent set of preferences-an internal predisposition to desire sexual interactions with members of one sex or another-and although commonly used to describe sexual identity in humans (see Glossary), it is rarely applied to other animals. In part, this is because it is impossible to know what animals 'desire'; we can only observe what they do. Individuals in a handful of vertebrate species have been described as having same-sex orientations, among them male chinstrap penguins (Pygoscelis antarcticus), which have been documented to form long-term pair bonds in captivity [15], and some male bighorn sheep (Ovis canadensis), which will only mount females if the females adopt male-like behavior [16]. Categorizing an individual animal's orientation is fraught with the added difficulty of not knowing for how long an animal must retain its sexual preference to be considered same- versus oppositesex oriented. Considering sexual orientation using this set of criteria is likely of limited use to biologists studying same-sex behavior in non-human animals.

\section{Causes of same-sex sexual behavior}

Published research on same-sex sexual behavior in animals has focused almost exclusively on two areas. The first area describes proximate mechanisms that underlie same-sex sexual behaviors. Such mechanistic studies have used model organisms such as Drosophila 
Table 2. Adaptive and non-adaptive explanations for same-sex sexual behavior

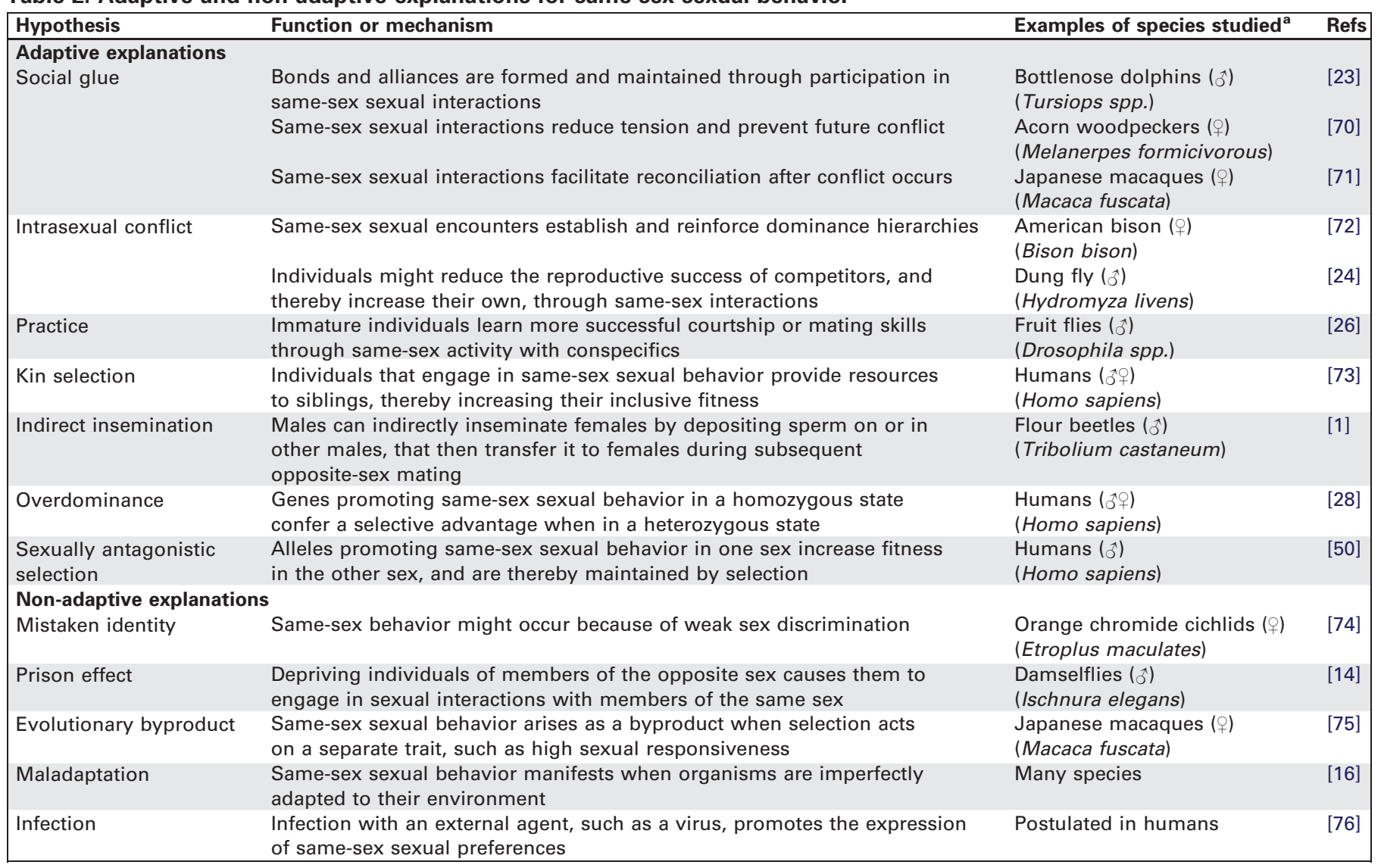

${ }^{a}$ The species listed in this table represent those in which the given hypothesis has been proposed or studied. Empirical studies have delivered varying levels of support for these hypotheses. For example, researchers have suggested that the tension-reduction hypothesis is unlikely to explain the persistence of female-female sexual behavior in Japanese macaques, but suggest instead that same-sex sexual behaviors might be induced by a tendency to seek interactions that are sexually gratifying [75]. In addition, the kin-selection hypothesis for the maintenance of same-sex behavior in humans has received little support (see Ref. [73] and references therein).

melanogaster, the nematode Caenorhabditis elegans and zebra finches to explore genetic, neurological, hormonal and social foundations of same-sex sexual interactions [17$21]$. Not all of these studies explicitly set out to examine same-sex behaviors, but research testing hypotheses about the formation of heterosexual partner preferences or sexual differentiation of the nervous system, for example, has spawned insights into genetic and physiological pathways that influence same-sex sexual behavior. Same-sex sexual behavior in Drosophila is clearly not comparable to that in bonobos, but studies of the neurophysiological control of sexual preferences in one organism can help to identify common mechanisms in other species, such as alteration in olfactory sex recognition or the importance of social experience in shaping subsequent mating behaviors.

The second major area of research has focused on the adaptive significance of same-sex sexual behavior (Table 2). The context in which this body of work has developed merits consideration. In the scientific literature, emphasis is often placed on the 'apparent paradox' $[1,2]$ that same-sex sexual behavior presents. It 'appears to be inconsistent with traditional evolutionary theory' [22] and 'seems to violate a basic "law" of nature: that of procreation' [3]. Attempts are then made to reconcile its existence with traditional selection theory by testing adaptive explanations, and these generally fall into three broad categories, as follows. (i) Same-sex sexual behavior provides the glue that establishes, maintains and strengthens social relationships, such as male alliances in bottlenose dolphins [23]. (ii) Same-sex sexual behavior provides a conduit for intensifying or diminishing intrasexual aggression and conflict. In the dung fly Hydromyza livens, for example, males have been hypothesized to mount other males to deny them the opportunity to mate, thereby increasing the likelihood that the mounting male obtains more mating opportunities [24]. By contrast, in the viviparous Goodeid fish Girardinichthys multiradiatus, males sometimes display a dark, female-like 'pregnancy' spot around their vent. Subordinate males with dark spots attract fewer aggressive maneuvers by dominant males, who appear to mistake them for females and consequently court them [25]. This diversion of aggressive behavior into courtship behavior affords subordinate males greater opportunities to sneak copulations with females [25]. (iii) Same-sex sexual encounters might provide younger animals with practice for courtship, mounting or other behaviors associated with reproduction, so as to improve their reproductive success when a heterosexual partner becomes available later on. Evidence from Drosophila supports a role of same-sex sexual experience in improving the outcome of later heterosexual mating encounters for young males, but not older males [26], and pink flamingoes might benefit from same-sex sexual experience by improving their territory-acquisition abilities [27]. 
In recent years, a handful of studies have sought to understand the causes of same-sex sexual behavior from a broader evolutionary perspective. MacFarlane et al. [22] surveyed same-sex sexual behavior in birds, and concluded that male-male sexual behavior was more commonly found in polygamous species, whereas female-female behavior was more likely to be observed in species with precocial young and a monogamous mating system. They suggested that same-sex behavior among males might be facilitated by proximity, as would occur in leks or other communal displays. And in one of the few attempts to model the selective forces that could lead to same-sex sexual behavior, Gavrilets and Rice [28] developed a set of theoretical predictions about the likely architecture of genes that might influence human homosexuality. The results of their theoretical study have wide-ranging consequences for our understanding of the evolution of same-sex sexual behavior in both humans and non-human species. For example, their models indicated a surprisingly wide range of genetic conditions under which genes influencing same-sex orientation in humans could propagate and persist, and predicted that individuals exhibiting both same-sex and opposite-sex sexual behaviors should be common [28] (see Table 2).

Those instances of same-sex sexual behavior that cannot be explained from an adaptationist perspective are often attributed to cases of mistaken identity, especially in invertebrates [29-31].

\section{Evolutionary consequences of same-sex sexual behavior}

There is no lack of hypotheses for how same-sex sexual behavior might be adaptive, and these hypotheses will vary greatly among species (Table 2). However, evolutionary consequences of same-sex sexual behavior have received scant attention. How do same-sex sexual interactions alter evolutionary dynamics within populations or species?

Same-sex sexual behavior is prevalent enough to influence the social dynamics of wild populations in some species but not others. In bottlenose dolphins (Thursiops sp.), for instance, roughly half of male sexual interactions are with other males [23]. Male-male mountings in the bearded vulture Gypaetus barbatus accounted for roughly 11-26\% of all mountings in one study [32], and in Japanese beetles (Popillia japonica), 1-6\% of all observed copulations were between males [33]. Recent studies in other wild populations suggest that these behaviors should not be dismissed as unimportant sources of selection (although see Ref. [34]).

Consider, for example, Laysan albatross. In 2008, researchers studying a colony of albatross in Hawaii reported that $31 \%$ of all pairs consisted of pair-bonded females that courted, allopreened and shared parenting responsibilities [35]. In this socially monogamous species, successfully rearing a chick requires the cooperation of two parents, and although the same-sex female pairs did not enjoy the level of reproductive success as their malefemale counterparts, they fared far better than unpaired females [35]. The sex ratio in the population was heavily female biased. If same-sex pair bonding and parenting are part of a flexible breeding strategy that females employ in response to dynamic social conditions such as sex-ratio fluctuations, then the alterations in social structure and social interactions within the population might also impact the evolutionary dynamics of the population.

One intriguing possibility is that female-female pairing increases the potential fitness benefits, and therefore selective advantage of, male extra-pair copulations. This is because there are more females available that can both participate in extra-pair copulations and provide care for the offspring afterward than there would be if all pairs in the population were opposite sex, or even if excess females remained unpaired. In addition, the likelihood of divorce might be weakened in populations where females exhibit the flexibility to form same-sex pairs and produce offspring. Same-sex pairing removes excess females from the population that would, under other circumstances, provide pressure for males in opposite-sex pairs to abandon their partner. The existence of female-female pairs in the albatross population-regardless of its genetic, hormonal or evolutionary causes - might therefore have evolutionary consequences. At any given time, such population-level consequences will depend on the degree of female flexibility and the population demographic factors that influence female pairing behavior. Furthermore, the importance of same-sex pairings is likely not limited to albatross; similar female-female pairings have been found in several other species, such as Roseate terns (Sternus dougallii) and California gulls (Larus californicus) [36,37].

It is clear that same-sex sexual behaviors occur in a wide variety of animal taxa, so predicting their evolutionary effects should be a key goal of future research. One way to do this would be to consider whether indirect genetic effects (IGEs) occur as a result of same-sex sexual behavior. IGEs occur when genes expressed in one individual alter the phenotype of another individual [38,39]. This can happen when two individuals have a social interaction, or when one individual modifies the environment in a way that influences another's phenotype. In the case of samesex sexual behavior, genes in one individual causing it to direct sexual behavior toward another member of the same sex could exert indirect effects on the second individual. For example, the second individual might experience either increased or reduced reproductive fitness, as in the albatross and dung fly examples, respectively $[35,24]$. Recent theoretical models have suggested that IGEs can, depending on the circumstances, dramatically strengthen or weaken evolutionary responses to selection $[38,39]$. In this sense, same-sex sexual behavior is both a trait that is potentially shaped by selection and a force that shapes selection on other traits.

For same-sex sexual behavior to be an IGE, however, it must have a heritable genetic basis. We are unaware of any published heritability estimates for same-sex sexual behavior in non-human animals, but estimates for human sexual orientation range as high as 0.74 [40] (see Box 2). Generating heritability estimates in a model organism would not only identify same-sex behaviors that are potential targets of selection but would also allow researchers to use quantitative genetic models incorporating IGEs to predict whether same-sex sexual behaviors alter the strength of selection on other traits. These could include 


\section{Box 2. Insights from studies of human homosexual orientation}

Since the publication of controversial research by Swaab and Hofman [48] and LeVay [49] in the early $1990 \mathrm{~s}$ that examined brain differences in homosexual versus heterosexual men, insights into the genetic, hormonal, neurophysiological and social contributions to sexual orientation in humans have accumulated rapidly. Humans make unique study organisms, because they can directly communicate with researchers and provide information that differentiates same-sex behavior from sexual orientation (see Glossary). Here we highlight advances in the study of same-sex behaviors in humans that have bearing on research goals addressing the patterns and processes that underlie same-sex behaviors in other animals:

- Twin/sibling studies. Studies examining the degree to which monozygotic, dizygotic and adopted siblings share their sexual orientation indicate that the tendency to be gay or lesbian is heritable and can run in families [40], and might confer a reproductive fitness advantage to the relatives of gay men [5053]. However, such studies are limited in their ability to elucidate the genetic architecture of traits such as sexual orientation.

- Linkage studies. Early studies on genes influencing sexual orientation suggested an association between male homosexual orientation and a marker on the $X$ chromosome [54-56]. Other researchers have had difficulty replicating these findings [57] (although see Ref. [58]), and a subsequent genome-wide linkage study identified several autosomal regions that potentially influence human sexual orientation [59].

- Fraternal birth-order effect. Having more older brothers increases the likelihood of a male being homosexual $[60,61]$. This pattern

behaviors such as courtship in Drosophila [25], or morphological features such as the armature found in both male and female African bat bugs (Afrocimex constrictus) that protects against traumatic insemination [30].

\section{Same-sex sexual behavior and sexual selection}

Sexual selection is characterized by competitive interactions that result in increased variation in mating success, and therefore increased variation in reproductive fitness [41]. It manifests either as intrasexual competition for mates or as intersexual mate choice, and can drive the evolution and maintenance of elaborate weaponry (in the case of intrasexual selection) or ornaments (in the case of intersexual selection). Because of its interactive nature, the outcome of sexual selection can be influenced by samesex sexual behavior in relatively intuitive ways. For example, some same-sex sexual behaviors appear to play a role in aggressive or dominance interactions, especially in males. In numerous genera and species of cockroaches, for example, males frequently elicit mountings by other males using stereotyped courtship maneuvers, or they might mimic female behaviors and mount courting males [42]. Such 'pseudofemale' behavior apparently increases the reproductive fitness of the males exhibiting it, because it increases the likelihood that they will mate with the female that had been courted by the displaced male. If a heritable genetic component underlies the tendency to engage in such interactions, the net effect can be to exaggerate or diminish the response to selection of traits that are involved in the interaction [38].

Same-sex sexual behavior as a channel for dominance interactions has been documented in other species such as dung flies [24], and although the behaviors might not have evolved as a mechanism of aggression, male-male mating attempts in desert locusts (Schistocerca gregaria) and might arise because of the pre-natal environment that fetuses experience, including compounds to which they are exposed in utero [62]. For example, maternal anti-male antibodies might aggregate during repeated pregnancies where the child is male, which in turn affect the sexual differentiation of a subsequent male fetus's brain.

- Sexual orientation and pheromones. In male homosexuals, regions of the brain that are associated with sexual activity activate in response to a testosterone derivative with pheromone-like properties [63]. An estrogen derivative similarly activated the same brain regions in homosexual women [64]. The responses are sex atypical, and researchers have begun to attribute such differences to anatomical features of the brain, for example amygdala connections, that are differentiated with respect to sexual orientation but not biological sex [65].

Homosexuality in humans is clearly not equivalent to, for example, male-male mountings in Japanese beetles; but, as with any other trait, it is useful to apply conceptual evolutionary frameworks that have been refined in one animal system, in this case humans, to other systems. For instance, twin studies in humans have provided estimates of the heritability of homosexual orientation, but heritability estimates for the tendency to exhibit same-sex behavior do not exist in any other species, to our knowledge. In model organisms such as flour beetles [1], such an approach could clarify whether the tendency to engage in same-sex sexual behavior can be a target of selection and have indirect effects on social evolution.

wasps (Lariophagus distinguendus) are similarly disadvantageous $[43,44]$. The consequence of these behaviors, regardless of their evolutionary cause, is selection for males to inhibit undesired courtship attempts. In the case of the locusts and wasps, this means releasing a pheromone that inhibits courtship by other males [43,44].

Is it logical, though, to treat these same-sex sexual behaviors as something separate from other behaviors or morphological traits that mediate intrasexual aggression? The only distinction is that they are sexual in character; they would normally be expressed in the context of an opposite-sex courtship or reproductive interaction, but are instead co-opted for another function. Thus, the evolutionary origins of same-sex sexual behaviors can be decoupled from their present function. It does not matter whether they arise as a byproduct of selection on other traits, genetic drift or millions of years of carefully honed adaptation driven by selection. They can have the same evolutionary consequences regardless of their independent causes. This highlights a key feature of same-sex sexual behaviors: they are flexibly deployed in a variety of circumstances, for example, as alternative reproductive tactics, as cooperative breeding strategies, as facilitators of social bonding or as mediators of intrasexual conflict. Once this flexibility is established, it becomes in and of itself a selective force that can shape selection on other aspects of physiology, life history, social behavior and even morphology.

\section{Concluding remarks}

For many people, the issue of same-sex sexual behavior in animals is more than just academic. Bagemihl's [16] compendium documenting same-sex behavior in nearly 450 species has been frequently cited in media articles and websites dealing with gay rights issues in humans $[45,46]$. 
It was even referenced by the American Psychiatric Association in evidence submitted to the US Supreme Court for consideration during the 2003 gay rights case Lawrence $v$. Texas, which overturned a Texas law banning homosexual sodomy [47]. It is crucial that scientific contributions from animal studies shed more light than heat on the topic of same-sex behavior, so it is useful to define promising directions for future work and identify pitfalls to avoid as the field matures.

Researchers have begun to achieve a firmer grasp on evolutionary explanations for the origin and maintenance of same-sex sexual behaviors. We advocate expanding the contexts in which same-sex sexual behavior is studied by exploring its evolutionary consequences. Same-sex interactions occur in an enormous variety of taxonomic groups, and both the mechanisms producing the behaviors and the outcomes of the behaviors can vary widely among and within species. Regardless of their proximate or evolutionary origins, viewing these behaviors as potential selective agents in and of themselves, and studying their evolutionary effects, would contribute insight into the general principles underlying phenomena such as cooperative breeding, aggression, conflict and sexual selection.

Several approaches appear promising. First, greater communication between researchers working on human sexual behavior and researchers engaged in non-human animal work would enhance the research programs of both (Box 2). These two fields can most effectively communicate with each other if efforts are made to avoid politicizing research results and drawing parallels between human sexual identity and animal behavior when they are clearly not merited. Second, models incorporating indirect genetic effects would be especially practical for quantifying the effects of same-sex sexual interactions on the rate and direction of selection, and particular emphasis should be placed on their effects on traits involved in reproductive isolation [38]. Third, and key to the second approach, heritability estimates for the tendency to engage in same-sex sexual behaviors are necessary to estimate the magnitude of these effects. It might be feasible to derive these from laboratory populations of model organisms that have already been shown to engage in same-sex sexual behaviors. Finally, by combining the above approaches with techniques that have been used to examine the evolutionary consequences of other behavioral or life-history traits, such as quantitative genetic and experimental evolution studies, we can achieve a richer understanding of how same-sex sexual behaviors do-or perhaps do not-contribute to social evolution and genetic and phenotypic diversification.

\section{Acknowledgements}

We thank T. Ly, D. McHugh, Ł.K. Michalczyk and K.G. Valente for encouragement and advice during early conversations about same-sex sexual behavior in animals. M.G. Ritchie gave valuable critiques on an early draft. Extensive comments from five reviewers and an editor helped improve the manuscript. This work was funded by an NSF grant to M.Z. and the UC Riverside Academic Senate.

\section{References}

1 Levan, K.E. et al. (2008) Testing multiple hypotheses for the maintenance of male homosexual copulatory behaviour in flour beetles. J. Evol. Biol. 22, 60-70
2 Santtila, P. et al. (2009) Testing Miller's theory of alleles preventing androgenization as an evolutionary explanation for the genetic predisposition for male homosexuality. Evol. Hum. Behav. 30, 58-65

3 Sommer, V. and Vasey, P.L., eds (2006) Homosexual Behaviour in Animals, Cambridge University Press

4 Gill, K.S. (1963) A Mutation Causing Abnormal Mating Behavior, Drosophila. Information Service

5 Greenspan, R.J. and Ferveur, J-F. (2000) Courtship in Drosophila. Annu. Rev. Genet. 34, 205-232

6 Zhang, S-D. and Odenwald, W.F. (1995) Misexpression of the white $(w)$ gene triggers male-male courtship in Drosophila. Proc. Natl. Acad. Sci. U. S. A. $92,5525-5529$

7 McRoberts, S.P. et al. (2003) Mutations in raised Drosophila melanogaster affect experience-dependent aspects of sexual behavior in both sexes. Behav. Genet. 33, 347-356

8 Grosjean, Y. et al. (2008) A glial amino-acid transporter controls synapse strength and courtship in Drosophila. Nat. Neurosci. 11, 54-61

9 Liu, T. et al. (2008) Increased dopamine level enhances male-male courtship in Drosophila. J. Neurosci. 28, 5539-5546

10 Kurtovic, A. et al. (2007) A single class of olfactory neurons mediates behavioural responses to a Drosophila sex pheromone. Nature 446, $542-546$

11 Miyamoto, T. and Amrien, H. (2008) Suppression of male courtship by a Drosophila pheromone receptor. Nat. Neurosci. 11, 874-876

12 Svetec, N. et al. (2005) Effect of genes, social experience, and their interaction on the courtship behaviour of transgenic Drosophila males. Genet. Res. 85, 183-193

13 Lee, H-G. et al. (2008) Recurring ethanol exposure induces disinhibited courtship in Drosophila. PLoS ONE 1, e1391

14 Van Gossum, H. et al. (2005) Reversible switches between male-male and male-female mating behaviour by male damselflies. Biol. Lett. 1, 268-270

15 Zuk, M. (2006) Family values in black and white. Nature 439, 917

16 Bagemihl, B. (1999) Biological Exuberance. St. Martin's Press

17 Adkins-Regan, E. (2002) Development of sexual partner preference in the zebra finch: a socially monogamous, pair-bonding animal. Arch. Sex. Behav. 31, 27-33

18 Svetec, N. and Ferveur, J-F. (2005) Social experience and pheromonal perception can change male-male interactions in Drosophila melanogaster. J. Exp. Biol. 208, 891-898

19 Baum, M.J. (2006) Mammalian animal models of psychosexual differentiation: when is 'translation' to the human situation possible? Horm. Behav 50, 579-588

20 Perkins, A. and Roselli, C.E. (2007) The ram as a model for behavioral neuroendocrinology. Horm. Behav. 52, 70-77

21 White, J.Q. (2007) The sensory circuitry for sexual attraction in $C$. elegans males. Curr. Biol 17, 1847-1857

22 MacFarlane, G.R. et al. (2007) Same-sex sexual behavior in birds: expression is related to social mating system and state of development at hatching. Behav. Ecol. 18, 21-33

23 Mann, J. (2006) Establishing trust: socio-sexual behaviour and the development of male-male bonds among Indian Ocean bottlenose dolphins. In Homosexual Behaviour in Animals (Sommer, V. and Vasey, P.L., eds), pp. 107-130, Cambridge University Press

24 Preston-Mafham, K. (2006) Post-mounting courtship and the neutralizing of male competitors through "homosexual" mountings in the fly Hydromyza livens F. (Diptera: Scatophagidae). J. Nat. Hist 40, 101-105

25 Macías-Garcia, C. and Valero, A. (2001) Context-dependent sexual mimicry in the viviparous fish Girardinichthys multiradiatus. Ethol. Ecol. Evol. 13, 331-339

26 McRobert, S.P. and Tompkins, L. (1988) Two consequences of homosexual courtship performed by Drosophila melanogaster and Drosophila affinis males. Evolution Int. J. Org. Evolution 42, 1093-1097

27 King, C.E. (2006) Pink flamingos: atypical partnerships and sexual activity in colonially breeding birds. In Homosexual Behaviour in Animals (Sommer, V. and Vasey, P.L., eds), pp. 77-106, Cambridge University Press

28 Gavrilets, S. and Rice, W.R. (2006) Genetic models of homosexuality: generating testable predictions. Proc. R. Soc. Lond. B Biol. Sci. 273, 3031-3038 
29 Harari, A.R. et al. (2000) Intrasexual mounting in the beetle Diaprepes abbreviatus (L.). Proc. R. Soc. Lond. B Biol. Sci 267, 2071-2079

30 Reinhardt, K. et al. (2007) Female-limited polymorphism in the copulatory organ of a traumatically inseminating insect. Am. Nat. $170,931-935$

31 Ambrogio, O.V. and Pechenik, J.A. (2008) When is a male not a male? Sex recognition and choice in two sex-changing species. Behav. Ecol. Sociobiol. 62, 1779-1786

32 Bertran, J. and Margalida, A. (2003) Male-male mountings in polyandrous bearded vultures Gypaetus barbatus: an unusual behaviour in raptors. J. Avian Biol. 34, 334-338

33 Switzer, P.V. et al. (2004) Effects of environmental and social conditions on homosexual pairing in the Japanese beetle (Popillia japonica Newman). J. Insect Behav. 17, 1-16

34 Shine, R. et al. (2003) Confusion within 'mating balls' of garter snakes: does misdirected courtship impose selection on male tactics? Anim. Behav 66, 1011-1017

35 Young, L.C. et al. (2008) Successful same-sex pairing in Laysan albatross. Biol. Lett. 4, 323-325

36 Nisbet, I.C.T. and Hatch, J.J. (1999) Consequences of a female-biased sex ratio in a socially monogamous bird: female-female pairs in the Roseate tern (Sterna dougallii). Ibis 141, 307-320

37 Conover, M.R. and Hunt, G.L., Jr (1984) Experimental evidence that female-female pairs in gulls result from a shortage of breeding males. Condor 86, 472-476

38 Moore, A.J. et al. (1997) Interacting phenotypes and the evolutionary process: I. Direct and indirect genetic effects of social interactions. Evolution Int. J. Org. Evolution 51, 1352-1362

39 Wolf, J.B. et al. (1998) Evolutionary consequences of indirect genetic effects. Trends Ecol. Evol. 13, 64-69

40 Pillard, R.C. and Bailey, J.M. (1998) Human sexual orientation has a heritable component. Hum. Biol. 70, 347-365

41 Andersson, M. and Simmons, L.W. (2006) Sexual selection and mate choice. Trends Ecol. Evol. 21, 296-302

42 Wendelken, P.W. and Barth, R.H., Jr (1985) On the significance of pseudofemale behavior in the neotropical cockroach genera Blaberus. Archimandrita and Byrsotria. Psyche (Stuttg.) 92, 493-504

43 Rono, E. et al. (2008) Concentration-dependent parsimonious releaser roles of gregarious male pheromone of the desert locust, Schistocerca gregaria. J. Insect Behav 54, 162-168

44 Ruther, J. and Steiner, S. (2008) Costs of female odour in males of the parasitic wasp Lariophagus distinguendus (Hymenoptera: Pteromalidae). Naturwissenschaften 95, 547-552

45 Soltaire, F. (2007) Agora Vox 11 April. (http://www.agoravox.fr/ article_tous_commentaires.php3?id_article=22111)

46 Anonymous blogger (2008) The Agonist 7 November. (http:// agonist.org/stirling_newberry/20081106/for_equal_marriage)

47 Gilfoyle, N.F.P. et al. (2003) Lawrence v. Texas (Docket no. 02-102). Brief Filed: 1/03. Court: Supreme Court of the United States. Year of Decision: 2003. (http://www.apa.org/psyclaw/lawrence-v-texas.pdf)

48 Swaab, D.F. and Hofman, M.A. (1990) An enlarged superchiasmatic nucleus in homosexual men. Brain Res. 537, 141-148

49 LeVay, S. (1991) A difference in hypothalamic structure between heterosexual and homosexual men. Science 253, 1034-1037

50 Camperio-Ciani, A. et al. (2004) Evidence for maternally inherited factors favouring male homosexuality and female fecundity. Proc. $R$. Soc. Lond. B Biol. Sci. 271, 2217-2221

51 King, M. et al. (2005) Family size in white gay and heterosexual men. Arch. Sex. Behav. 34, 117-122

52 Rahman, Q. et al. (2008) Maternal inheritance and familial fecundity factors in male homosexuality. Arch. Sex. Behav. 37, 962-969

53 Zeitsch, B.P. (2008) Genetic factors predisposing to homosexuality may increase mating success in heterosexuals. Evol. Hum. Behav. 29, 424 433
54 Hamer, D.H. et al. (1993) A linkage between DNA markers on the X chromosome and male sexual orientation. Science 261, 321-327

$55 \mathrm{Hu}$, S. et al. (1995) Linkage between sexual orientation and chromosome Xq28 in males but not in females. Nat. Genet. 11, 248-256

56 Hamer, D. (2002) Molecular genetics and the human personality. In Genetics of Sexual Behavior (Benjamin, J. et al., eds), pp. 257-272, American Psychiatric Publishing

57 Rice, G. et al. (1999) Male homosexuality: absence of linkage to microsatellite markers at Xq28. Science 284, 665-667

58 Bocklandt, S. et al. (2006) Extreme skewing of X chromosome inactivation in mothers of homosexual men. Hum. Genet. 118, 691-694

59 Mustanski, B.S. et al. (2005) A genomewide scan of male sexual orientation. Hum. Genet. 116, 272-278

60 Blanchard, R. and Bogaert, A.F. (2004) Proportion of homosexual men who owe their sexual orientation to fraternal birth order: an estimate based on two national probability samples. Am. J. Hum. Biol. 16, 151157

61 Blanchard, R. (2004) Quantitative and theoretical analyses of the relation between older brothers and homosexuality in men. $J$. Theor. Biol. 230, 173-187

62 Bogaert, A.F. (2006) Biological versus nonbiological older brothers and men's sexual orientation. Proc. Natl. Acad. Sci. U. S. A. 103, 1077110774

63 Savic, I. et al. (2005) Brain response to putative pheromones in homosexual men. Proc. Natl. Acad. Sci. U. S. A. 102, 7356-7361

64 Berglund, H. et al. (2006) Brain response to putative pheromones in lesbian women. Proc. Natl. Acad. Sci. U. S. A. 103, 8269-8274

65 Savic, I. and Lindström, P. (2008) PET and MRI show differences in cerebral asymmetry and functional connectivity between homoand heterosexual subjects. Proc. Natl. Acad. Sci. U. S. A. 105, 94039408

66 Fruth, B. and Hohmann, G. (2006) Social grease for females? Same-sex genital contacts in wild bonobos. In Homosexual Behaviour in Animals (Sommer, V. and Vasey, P.L., eds), pp. 294-315, Cambridge University Press

67 Marco, A. and Lizana, M. (2002) The absence of species and sex recognition during mate search by male common toads. Bufo bufo. Ethol. Ecol. Evol. 14, 1-8

68 Field, K.L. and Waite, T.A. (2004) Absence of female conspecifics induces homosexual behaviour in male guppies. Anim. Behav. 68, 1381-1389

69 Price, E.O. et al. (1988) The relationship of male-male mounting to the sexual preferences of young rams. Appl. Anim. Behav. Sci. 21, 347355

70 MacRoberts, M.H. and MacRoberts, B.R. (1976) Social Organization and Behavior of the Acorn Woodpecker in Central Coastal California (Ornithology Monographs, Vol. 21), American Ornithologists' Union

71 Vasey, P.L. et al. (1998) Mounting interactions between female Japanese macaques: testing the influence of dominance and aggression. Ethology 104, 387-398

72 Vervaecke, H. and Roden, C. (2006) Going with the herd: same-sex interaction and competition in American bison. In Homosexual Behaviour in Animals (Sommer, V. and Vasey, P.L., eds), pp. 131153, Cambridge University Press

73 Rahman, Q. and Hull, M.S. (2005) An empirical test of the kin selection hypothesis for male homosexuality. Arch. Sex. Behav. 34, 461-467

74 Barlow, G.W. (2000) The Cichlid Fishes: Nature's Grand Experiment in Evolution. Perseus

75 Vasey, P.L. et al. (2008) Courtship behaviour in Japanese macaques during heterosexual and homosexual consortships. Behav. Processes $78,401-407$

76 Cochran, G.M. et al. (2000) Infectious causation of disease: an evolutionary perspective. Perspect. Biol. Med. 43, 406-448 